\title{
Development and application of an indirect ELISA for the detection of antibodies against encephalomyocarditis virus
}

\author{
$\mathrm{LI} \mathrm{ZHANG}^{1 *}, \mathrm{YAN} \mathrm{QI}^{2-4^{*}}, \mathrm{LI} \mathrm{LUO}^{1 *}, \mathrm{JIGUO} \mathrm{SUN}^{2-4}$ and WANZHE YUAN ${ }^{2-4}$ \\ ${ }^{1}$ Department of Anatomy, School of Basic Medicine, Guangdong Pharmaceutical University, Guangzhou, Guangdong 510006; \\ ${ }^{2}$ College of Animal Medicine, Agricultural University of Hebei; ${ }^{3}$ Hebei Engineering and Technology Research Center of \\ Veterinary Biotechnology; ${ }^{4}$ North China Research Center of Animal Epidemic Pathogen Biology, \\ China Agriculture Ministry, Baoding, Hebei 071001, P.R. China
}

Received April 24, 2017; Accepted June 22, 2017

DOI: $10.3892 /$ br.2017.989

\begin{abstract}
Encephalomyocarditis virus (EMCV) can cause acute myocarditis in young pigs or reproductive failure in sows. It has been recognized worldwide as a pathogen infecting many species and causes substantial economic losses. In the present study, an indirect ELISA was developed for the detection of antibodies to EMCV. The VP1 gene of EMCV was amplified by reverse transcription-quantitative polymerase chain reaction and expressed in Escherichia coli with $49.3 \mathrm{kDa}$ under the condition of isopropyl- $\beta$-d-thiogalactoside. Following this, the authors obtained the recombinant protein VP1 as a coating antigen. The antigen concentration and serum dilution were optimized using a checkerboard titration. Compared with viral neutralization tests, the sensitivity and specificity of the indirect ELISA was $95.7 \%$ and $92.9 \%$, respectively. A total of 265 clinical swine serum samples from different pig farms in China were used to a serological survey. The seropositive rate of the serum samples was $81.9 \%$. In conclusion, the developed indirect ELISA assay is sensitive and specific, which will be useful for large-scale serological survey in EMCV infection and monitoring antibodies titers against EMCV.
\end{abstract}

\section{Introduction}

Encephalomyocarditis virus (EMCV), a member of the genus Cardiovirus in the family Picornaviridae, is a single-stranded

Correspondence to: Professor Wanzhe Yuan, College of Animal Medicine, Agricultural University of Hebei, 289 Lingyusi Street, Baoding, Hebei 071001, P.R. China

E-mail: yuanwanzhe@163.com

*Contributed equally

Abbreviations: EMCV, encephalomyocarditis virus; ELISA, enzyme-linked immunosorbent assay; IPTG, isopropyl- $\beta$-d-thiogalactoside

Key words: encephalomyocarditis virus, indirect ELISA, VP1, antibodies positive-sense RNA virus of $\sim 7.8 \mathrm{~kb}$ in length with a large open reading frame (ORF) (1). It contains a $5^{\prime}$ untranslated region (5' UTR) and a $3^{\prime}$ untranslated region (3' UTR). The ORF encodes for 11 proteins, including four structural proteins (VP1, VP2, VP3, VP4), seven non-structural proteins (2A, 2B, 2C, 3A, 3B, 3C, 3D) and a leader protein. The VP1 region, which is highly variable, is an important protective antigen of EMCV (2). It can stimulate the body to produce neutralizing antibodies. It is also the important region for researching gene vaccine (3).

EMCV has been recognized worldwide as a pathogen infecting many species, including pigs, cattle, rodents, raccoons, elephants, marsupials and primates such as baboons, chimpanzees, monkeys, and even humans (4-7). The virus, which currently affects the global swine industry, can cause myocarditis, reproductive failure and high mortality in pregnant sows, fetuses and weaning piglets. In China, it had been confirmed that EMCV infection occurs in many pig farms by the methods of etiology and serology (8).

In the current study, the authors used the reverse transcription-quantitative polymerase chain reaction method to successfully amplify the full-length VP1 coding sequence. They subsequently produced the recombinant gene product in the Escherichia coli expression system, which is commonly used to produce adequate amounts of protein suitable for the intended application. E. coli is easy to transform, grows quickly in simple media, and requires inexpensive equipment for growth and storage. The produced recombinant VP1 was then used to develop an indirect ELISA assay with sensitivity and specificity comparable to virus neutralization tests.

\section{Materials and methods}

RNA isolation. EMCV strain BD2 (KF709977) was isolated from three clinically ill newborn pigs, which exhibited anorexia, rapid breathing and acute myocarditis, from a commercial pig farm in Hebei, China, as described previously (9). BHK-21 cells were grown in $75 \mathrm{~cm}^{2}$ plastic flasks, inoculated with $1 \mathrm{ml}$ of virus supernatant from positive cell cultures. After an extensive cytopathic effect was observed, frozen and thawed three times and centrifuged at $13,400 \times \mathrm{g}$ for $10 \mathrm{~min}$ at $4^{\circ} \mathrm{C}$. 
Genomic RNA of EMCV BD2 was extracted from the cultural supernatant of infected BHK-21 cells using the EasyPure Viral DNA/RNA kit (Beijing Transgen Biotech Co., Ltd., Beijing, China) according to the manufacturer's instructions.

Amplification of the EMCV VP1 gene. The VP1 gene was amplified by RT-qPCR using the template from the last step. The genome sequence of the BD2 strain EMCV-VP1 has been uploaded to the NCBI (accession no. KF709977.1).

The forward primer contained a BamHI restriction site at the 5 '-end of the sequence coding for VP1, while the reverse primer contained an XhoI site positioned after the stop codon at the 3'-end. The sequences of the primers were as follows: forward, 5'-CGCGGATCCGGAGTAGAAAACGCTGAAAAAG-3' and reverse, 5'-CCGCTCGAGCTCTAGCATCAAGACTCCA GCT-3'. Both primers were purchased from Sangon Biotech Co., Ltd. (Shanghai, China) and used without further purification. The PCR reaction mixture included $1 \mu \mathrm{g}$ DNA template, $1 \mu \mathrm{l}$ PrimeSTART HS DNA Polymerase (Takara Biotechnology Co., Ltd., Dalian, China), $10 \mu 1$ 5X PrimeSTART buffer (Beyotime Institute of Biotechnology, Haimen, China), all four dNTPs at final concentrations of $0.2 \mathrm{mM}$ each, primers at a final concentration of $0.2 \mu \mathrm{M}$ each, and $\mathrm{ddH}_{2} \mathrm{O}$ in a total volume of $50 \mu \mathrm{l}$. The cycling conditions included an initial denaturation step at $98^{\circ} \mathrm{C}$ for $30 \mathrm{sec}$, and then 30 cycles consisting of $30 \mathrm{sec}$ denaturation at $98^{\circ} \mathrm{C}, 30 \mathrm{sec}$ annealing at $56^{\circ} \mathrm{C}$, and $50 \mathrm{sec}$ extension at $72^{\circ} \mathrm{C}$, followed by a final extension for $10 \mathrm{~min}$ at $72^{\circ} \mathrm{C}$. The amplification product was purified on a $1 \%(\mathrm{w} / \mathrm{v})$ agarose gel in TAE buffer, stained with ethidium bromide, and extracted using a commercial kit (QIAquick Gel Extraction kit; Sangon Biotech Co., Ltd.), according to the manufacturer's instructions.

Construction of recombinant proteins. Following extraction, the DNA product and the expression vector pET32a plasmid were each digested with BamHI and XhoI using standard molecular biology protocols. The VP1 DNA insert (55 ng) and linearized pET32a (20 ng) were incubated at $16^{\circ} \mathrm{C}$ overnight in the presence of $1 \mu \mathrm{l} 4$ DNA ligase in a total volume of $10 \mu \mathrm{l}$ according to the manufacturer's instructions.

The entire ligation reaction was transformed into Trans1-T1 chemically competent cells (Beijing Transgen Biotech Co.). Several colonies were screened for the presence of EMCV VP1 DNA by colony PCR; colonies that were positive were grown in liquid culture and plasmids were purified using a TIANprep Mini Plasmid kit (Tiangen Biotech Co., Ltd., Beijing). The presence of EMCV VP1 DNA was confirmed by restriction digests of the purified plasmids, and plasmids were sequenced to confirm that the correct sequence had been inserted. In addition, the specificity of VP1 was confirmed via cross-reactivity using ELISA kits for classical swine fever virus (cat. no. SL0002Po; Sunglong Biotech Co., Ltd., Hangzhou, China), porcine respiratory and reproductive syndrome virus (cat. no. KA2120; Abnova, Taipei, Taiwan), pseudorabies virus (cat. no. PRV041117A; Zhejiang Gloria Bioscience, Co., Ltd., Hangzhou, China) and porcine circovirus type 2 virus (cat. no. AE-200150-2; Alpha Diagnostic International, Inc., Texas, USA).

The expression plasmid was then transformed into BL21(DE3) chemically competent cells (Takara Biotechnology,
Co., Ltd.). Colonies that were positive were grown in liquid culture. Following confirmation of the correct sequence, the bacteria were expanded on a large scale and preserved with $50 \%$ glycerinin normal saline at $-20^{\circ} \mathrm{C}$.

Protein expression and analysis. A small culture $(15 \mathrm{ml})$ of LB media containing $100 \mu \mathrm{g} / \mathrm{ml}$ ampicillin was inoculated with $150 \mu \mathrm{l}$ preserved bacteria. After shaking at $37^{\circ} \mathrm{C}$ for 2-3 h, the optical density (OD) of the culture at $600 \mathrm{~nm}$ reached 0.6-0.8. At this point, $1 \mathrm{ml}$ of the culture was collected before addition of isopropyl- $\beta$-D-1-thiogalactopyranoside (IPTG) to a final concentration of $1 \mathrm{mM}$. Then expression was measured for several hours at $37^{\circ} \mathrm{C}$ with shaking, and cultures were harvested at every hour. The control was the non-carrier of pET32a that was induced by IPTG for $5 \mathrm{~h}$. All of the cultures were centrifuged for $3 \mathrm{~min}$ at 9,000 x g. Following centrifugation, the supernatant was discarded. Pellets were resuspended in $50 \mu 12 \mathrm{X} \mathrm{SDS}$ buffer and degenerated at $100^{\circ} \mathrm{C}$ for $10 \mathrm{~min}$. Following centrifugation for $3 \mathrm{~min}$ at $9,000 \mathrm{x} \mathrm{g}$, the supernatant were run on a $12 \%$ SDS-PAGE gel. Finally, the recombinant protein activity was analyzed by western blotting. For western blotting, the cells were rinsed three times with PBS, lysed with radioimmunoprecipitation assay lysis buffer (Beyotime Institute of Biotechnology) and incubated on ice for $30 \mathrm{~min}$. The lysates were then centrifuged at $13,400 \mathrm{x} \mathrm{g}$ for $20 \mathrm{~min}$ at $4^{\circ} \mathrm{C}$ and the supernatant extracts were quantified for the total protein using a Bicinchoninic Acid Protein Assay kit (Beyotime Institute of Biotechnology) with bovine serum albumin as the standard. Aliquots from each protein lysate sample were separated in 12\% SDS-PAGE and transferred to a polyvinylidene difluoride membrane. The membrane was blocked with blocking buffer (TBS and $5 \%$ skimmed milk) for $1 \mathrm{~h}$ at room temperature and incubated overnight in the presence of rabbit anti-foot and mouth disease virus polyprotein (VP1 protein) primary antibody (1:800; cat. no. PL0301542; PL Laboratories, Inc., Port Moody, Canada) at $4^{\circ} \mathrm{C}$. The membrane was washed three times with TBS containing $0.05 \%$ Tween-20 (TBST) and subsequently reacted with anti-rabbit immunoglobulin $\mathrm{G}(\mathrm{IgG} ; \mathrm{H}+\mathrm{L})$ conjugated to horseradish peroxidase (HRP; 1:800; cat. no. E030120; EarthOx, LLC, Millbrae, CA, USA) for $1 \mathrm{~h}$ at room temperature. Following thorough washing with TBST, the immunoreactive bands were developed using enhanced chemiluminescence detection reagents (EMD Millipore, Billerica, MA, USA). The OD of the bands on the films was analyzed using imaging software (ImageQuant Las 4000, version 1.2; GE Healthcare Life Sciences, Chalfont, UK).

Recombinant protein (VP1) purification and analysis. According to the optimal condition, a small culture $(10 \mathrm{ml})$ of LB media containing $100 \mu \mathrm{g} / \mathrm{ml}$ ampicillin was inoculated with $10 \mu \mathrm{l}$ preserved bacteria. After shaking overnight at $37^{\circ} \mathrm{C}$, the small culture was added to $500 \mathrm{ml} \mathrm{LB}$ media (with antibiotics at the concentrations used for the small culture) and incubated at $37^{\circ} \mathrm{C}$ with agitation until the OD of the culture at $600 \mathrm{~nm}$ reached 0.6-0.8. At this point, the culture was allowed to add IPTG to a final concentration of $1 \mathrm{mM}$. Expression was allowed for several hours at $37^{\circ} \mathrm{C}$ with shaking, and cultures were harvested at the optimal time by centrifugation for $20 \mathrm{~min}$ at $9,000 \mathrm{x}$. The pellets were stored at $-80^{\circ} \mathrm{C}$ until 


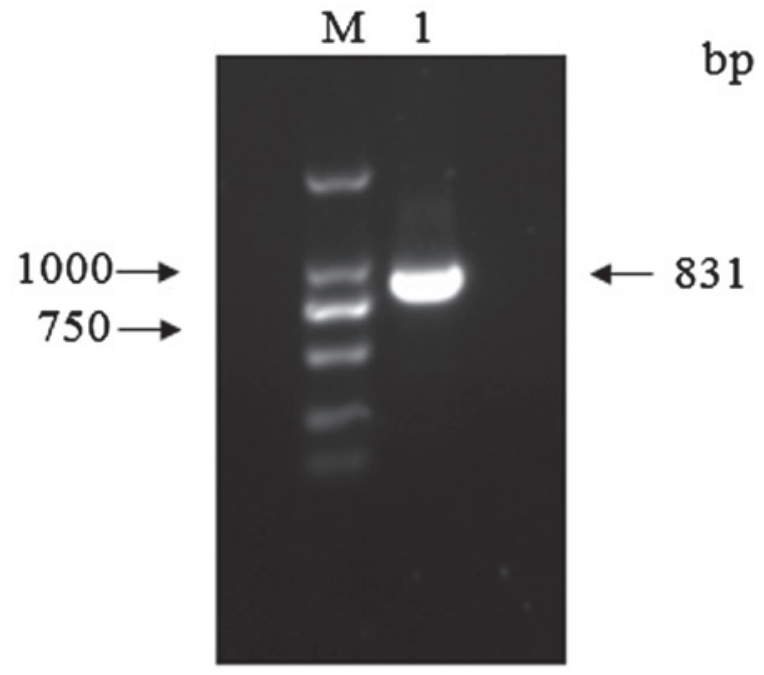

Figure 1. Data graph of VP1 amplification from encephalomyocarditis virus by reverse transcription-quantitative PCR. Lane 1, VP1 gene. The approximate size of the PCR product (right) corresponds to the projected size of 831 bp. M, 2,000 bp DNA Marker. PCR, polymerase chain reaction.

purification took place. In addition, the purification of VP1 was conducted under a low temperature environment, a condition of non degeneration.

The pellets ( 1.0 g wet weight, representing $500 \mathrm{ml}$ liquid culture) were thawed on ice and resuspended completely in $20 \mathrm{ml}$ lysis buffer (Beyotime Institute of Biotechnology). The cells were sonicated on ice using 10 cycles of the following sequence: $1 \mathrm{sec}$ on, $1 \mathrm{sec}$ off for $20 \mathrm{sec}$; rest on ice for $40 \mathrm{sec}$. The lysate was centrifuged at $13,400 \mathrm{x}$ g for $15 \mathrm{~min}$ at $4^{\circ} \mathrm{C}$, and the pellet was collected. The solid white pellet was gently and completely resuspended on ice with $10 \mathrm{ml}$ binding buffer [20 mMTris(2-carboxyethyl)phosphine- $\mathrm{HCl} \mathrm{pH}$ 7.9, $5 \mathrm{mM}$ imidazole, $0.5 \mathrm{M} \mathrm{NaCl}, 8 \mathrm{M}$ urea]. Then centrifuged at $13,400 \mathrm{x}$ g for $20 \mathrm{~min}$ at $4^{\circ} \mathrm{C}$. Following centrifugation, the supernatant was collected. The solution was added to a column containing $1 \mathrm{ml}$ complete His-Tag Purification resin (CWBIO, Beijing, China) and washed extensively with binding buffer containing $5 \mathrm{mM}$ imidazole. EMCV VP1 protein was eluted in elution buffer (Beyotime Institute of Biotechnology); two elution buffers (10 ml each, containing 200 and $500 \mathrm{mM}$ imidazole, respectively) were added sequentially to the column, and the elute was collected in $5 \mathrm{ml}$ fractions. Fractions were then run on a 12\% SDS-PAGE gel.

Development of the indirect ELISA-VP1. Optimal dilutions of VP1 and sera were determined by a checkerboard titration test with EMCV positive and negative sera previously analyzed by virus neutralization tests. The antibody of VP1 has neutralizing activity, and it was confirmed that the virus did not exist in the negative sera. The antigen was coated in 96-well ELISA plates and diluted in $0.05 \mathrm{~mol} / 1$ carbonate buffer $(\mathrm{pH} 9.6)$ to $1: 100,1: 200,1: 400,1: 800,1: 1,600$ and 1:3,200. Reference positive and negative sera were both diluted in 1:10, 1:20, 1:40 and 1:80, respectively, and tested to determine the optimal serum dilution. The dilutions that gave the maximum difference in absorbance at $450 \mathrm{~nm}$ between the positive and the negative sera $(\mathrm{P} / \mathrm{N})$ were selected to test the sera panel. The working dilution of rabbit anti-swine horseradish peroxidase (HRP)-IgG (Beijing Solarbio Science \& Technology Co., Ltd., Beijing, China), the reaction temperature, time and other conditions also were optimized.

Carbonate buffer solution (0.05 mol/1, $\mathrm{pH} 9.6)$ served as coating buffer. The antigen was diluted to $0.605 \mu \mathrm{g} / \mathrm{ml}$ and coated on 96-well microtiter plates with $100 \mu$ l, overnight at $4^{\circ} \mathrm{C}$. The plates were washed three times for 5 min with PBS and 0.5\% Tween-20 (PBS-T). Then, the plates were blocked with blocking buffer [Tris-buffered saline (TBS) and $5 \%$ skimmed milk] at $37^{\circ} \mathrm{C}$ for $1 \mathrm{~h}$ followed by a washing step. Subsequently, $100 \mu 1$ sera was diluted (1:40) in dilution buffer and incubated at $37^{\circ} \mathrm{C}$ for $1 \mathrm{~h}$ followed by a washing step. A total of volume of $50 \mu \mathrm{l} \mathrm{HRP-labeled} \mathrm{rabbit-anti-swine} \mathrm{protein}$ IgG (1:800; cat. no. E030110; EarthOx, LLC) was added to all wells and incubated at $37^{\circ} \mathrm{C}$ for $1 \mathrm{~h}$. After washing again, $100 \mu \mathrm{l}$ freshly prepared substrate solution $(1 \mathrm{mg} / \mathrm{ml}$ tetramethylbenzidine that contained $3 \mu 130 \%$ hydrogen peroxide) was dispensed into each well. Color development was in the dark for $15 \mathrm{~min}$, and the reaction was stopped by addition of $50 \mu \mathrm{l}$ $2 \mathrm{M}$ sulfuric acid. The absorbance values were read at $450 \mathrm{~nm}$ using an absorbance microplate reader (BioTek Instruments, Inc., Winooski, VT, USA).

To determine the cut-off value of the ELISA-VP1, 20 samples of SPF swine serum was obtained and the dilution was 1:40. The test for indirect ELISA is done in the optimal conditions. The result was analyzed by statistics to achieve the average value, $\mathrm{X}$, and the standard deviation, $\mathrm{S}$. The samples with OD $450 \geq X+3 S$ were positive. The samples with OD $450<\mathrm{X}+3 \mathrm{~S}$ were negative.

Comparison of the indirect ELISA with the virus neutralization tests. A total of 120 sera samples were obtained from different swine herds in Baoding, China. They were tested to evaluate the correlation between the neutralization test and the indirect ELISA.

Quality assurance and repeatability of ELISA. The repeatability (intra-plate variability) was assessed by the same analyst who tested five sera samples, four times, on the same plate, on the same day. The mean and coefficients of variation (CVs) were computed using Excel 2003 (Microsoft Corporation, Redmond, WA, USA).

The reproducibility (inter-plate variability) of the test results was assessed by testing five sera samples 10 times. The results were obtained by use of distinct lots, on different days, by different analysts. The mean and CVs were computed.

Field application of VP1-ELISA in clinical samples. During 2013 and 2014, a total of 265 clinical swine serum samples were collected from pig farms in surrounding of Baoding, China. According to the established indirect ELISA method, they were detected for the EMCV antibody.

\section{Results}

PCR amplification and sequencing of the EMCV VPl gene. The VP1 DNA was amplified with primers designed to insert a BamHI restriction site at the 5'-end of the sequence and an XhoI site at the 3 '-end. Analysis of the reaction products by agarose 


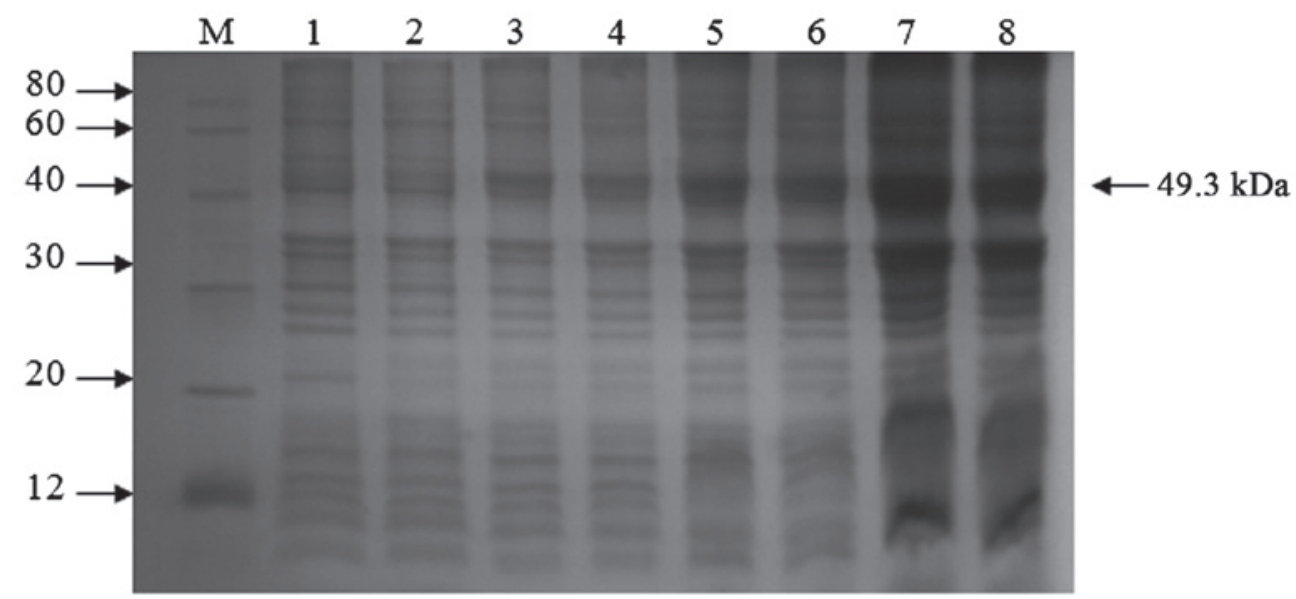

Figure 2. SDS-PAGE analysis of recombinant VP1 protein expressed in pET32a. Lane 1, pET32a/BL21 induced with IPTG(5h); lane 2, pET32a- VP1/BL21 without induction with IPTG; lanes 3-8, pET-32a-VP1/ BL21 induced with IPTG for 1, 2, 3, 4, 5 and 6 h, respectively. M, molecular weight marker; IPTG, isopropyl- $\beta$-d-thiogalactoside.

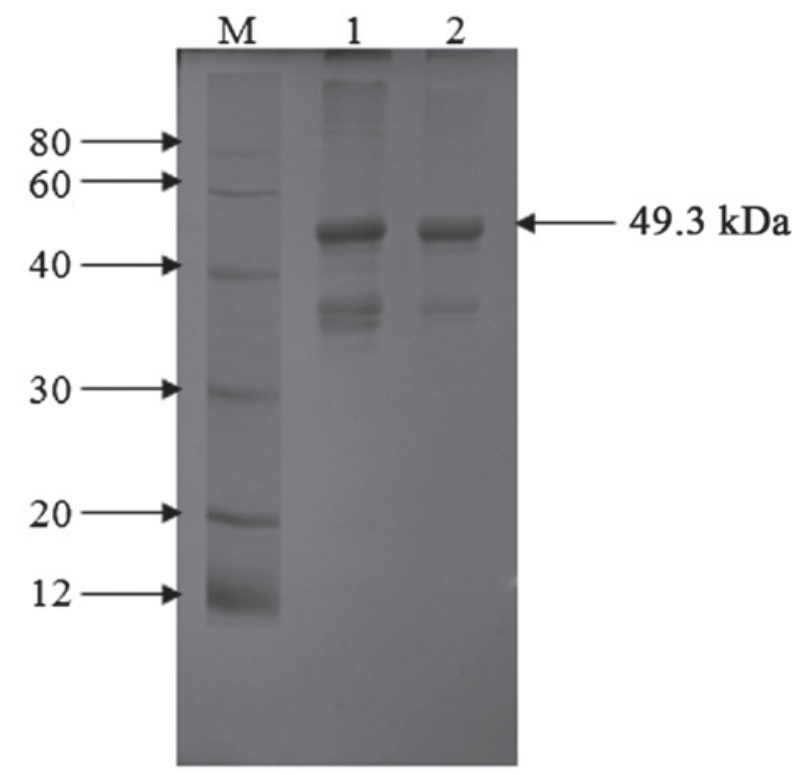

Figure 3. Samples from Ni-NTA purification run on SDS-PAGE (12\%). M, molecular weight marker; lane 1, eluate using $200 \mathrm{mM}$ imidazole; lane 2, eluate using $500 \mathrm{mM}$ imidazole.

gel electrophoresis and ethidium bromide staining revealed a specific amplimer of the expected size, $\sim 831$ bp (Fig. 1).

Expression and purification of VP1. Following digestion, ligation and sequencing, the plasmid was transformed into BL21(DE3) chemically competent cells for expression. Expression was induced at $37^{\circ} \mathrm{C}$ and was allowed to continue for $6 \mathrm{~h}$. SDS-PAGE analysis of the samples indicated that the control of pET32a induced for $5 \mathrm{~h}$ and the non-induced recombinant VP1 protein did not have target bands. The cultures that were induced by IPTG every hour show that a target band appeared and the optimal expression time of VP1 protein is $5 \mathrm{~h}$ (Fig. 2). Following purification using Ni-NTA, fractions were run on a 12\% SDS-PAGE gel, where the majority of pure VP1 protein was found to elute at $500 \mathrm{mM}$ imidazole (Fig. 3). Western blotting with an anti-EMCV VP1 monoclonal antibody revealed a specific band of the same size (Fig. 4). By purifying, $0.484 \mathrm{mg} / \mathrm{ml}$ recombinant VP1 protein

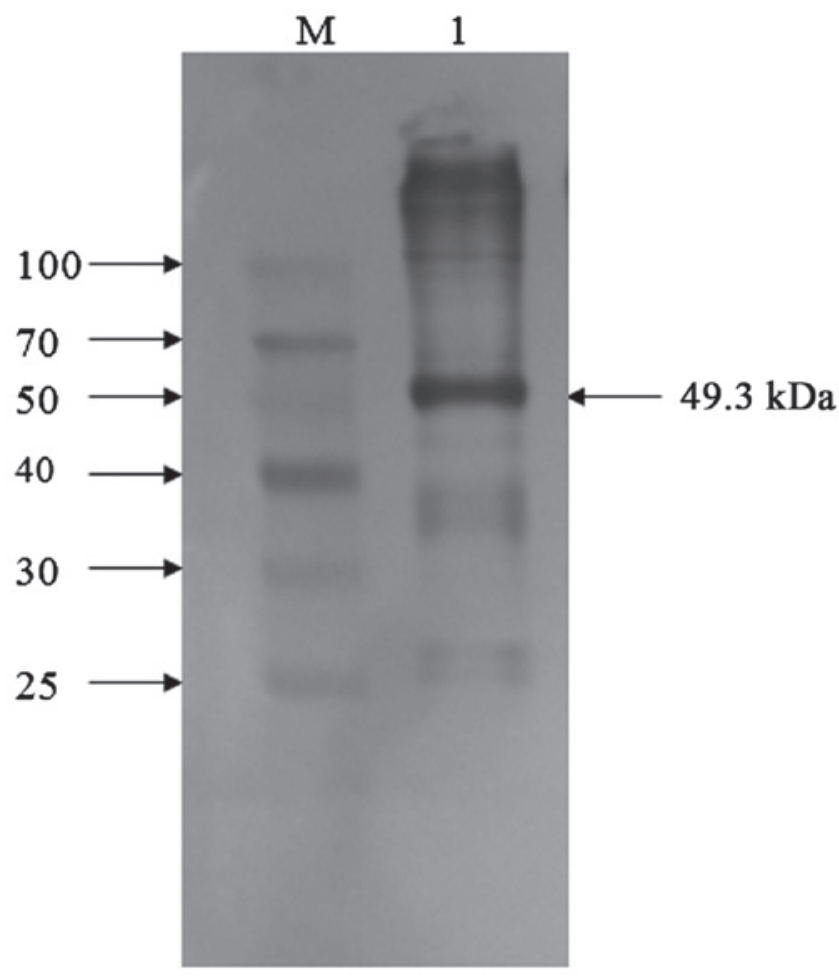

Figure 4. Western blot analysis of recombinant VP1 protein expressed in pET-32a. M, prestained molecular weight marker; lane 1,recombinant VP1 protein.

was obtained then stored in $-80^{\circ} \mathrm{C}$. The positive immunoblotting results suggested that could recombinant EMCV VP1 expressed and purified in Escherichia coli could be used to develop an indirect ELISA test.

ELISA-VP1. By using checkerboard titration tests, the OD value gave the maximum difference between the positive serum and negative serum $(\mathrm{P} / \mathrm{N}$ value of 5.62) when the dilutions of antigen and serum were 1:800 and 1:40, respectively (Table I). Therefore, the final concentration of coating antigen was $0.605 \mu \mathrm{g} / \mathrm{ml}$ by calculation, and the optimal dilution of the HRP-IgG was 1:800 (Table II). A total of 20 samples of 
Table I. Determination of the coating concentration of antigen and the dilution of serum samples.

\begin{tabular}{|c|c|c|c|c|c|c|}
\hline \multirow[b]{2}{*}{ Serum dilution } & \multicolumn{6}{|c|}{ OD of positive serum with different coating antigen dilutions of recombinant VP1 } \\
\hline & $1: 100$ & $1: 200$ & $1: 400$ & $1: 800$ & $1: 1,600$ & $1: 3,200$ \\
\hline \multicolumn{7}{|l|}{$1: 20$} \\
\hline $\mathrm{P}$ & 1.465 & 1.351 & 1.280 & 1.120 & 0.982 & 0.991 \\
\hline $\mathrm{N}$ & 0.442 & 0.402 & 0.339 & 0.320 & 0.252 & 0.252 \\
\hline $\mathrm{P} / \mathrm{N}$ & 3.31 & 3.36 & 3.78 & 3.50 & 3.90 & 3.93 \\
\hline \multicolumn{7}{|l|}{$1: 40$} \\
\hline $\mathrm{P}$ & 1.301 & 1.230 & 1.185 & 1.063 & 0.895 & 0.792 \\
\hline $\mathrm{N}$ & 0.377 & 0.334 & 0.299 & 0.189 & 0.170 & 0.154 \\
\hline $\mathrm{P} / \mathrm{N}$ & 3.45 & 3.68 & 3.96 & 5.62 & 5.26 & 5.14 \\
\hline \multicolumn{7}{|l|}{$1: 80$} \\
\hline $\mathrm{P}$ & 1.086 & 0.982 & 0.931 & 0.883 & 0.802 & 0.647 \\
\hline $\mathrm{N}$ & 0.319 & 0.276 & 0.251 & 0.228 & 0.175 & 0.148 \\
\hline $\mathrm{P} / \mathrm{N}$ & 3.40 & 3.56 & 3.71 & 3.87 & 4.58 & 4.37 \\
\hline \multicolumn{7}{|l|}{$1: 160$} \\
\hline $\mathrm{P}$ & 0.902 & 0.852 & 0.780 & 0.670 & 0.602 & 0.591 \\
\hline $\mathrm{N}$ & 0.288 & 0.226 & 0.208 & 0.190 & 0.148 & 0.138 \\
\hline $\mathrm{P} / \mathrm{N}$ & 3.13 & 3.77 & 3.75 & 3.53 & 4.07 & 4.28 \\
\hline
\end{tabular}

$\mathrm{OD}$, optical density; $\mathrm{P} / \mathrm{N}$, ratio between positive and negative sera.

Table II. Determination of the optimal working concentration of HRP-labeled rabbit anti-swine IgG.

\begin{tabular}{lccc}
\hline $\begin{array}{l}\text { HRP-labeled } \\
\text { dilution }\end{array}$ & $\begin{array}{c}\text { Positive } \\
\text { serum(Ab) }\end{array}$ & $\begin{array}{c}\text { Negative } \\
\text { serum(Ab) }\end{array}$ & P/N value \\
\hline $1: 200$ & 1.327 & 0.276 & 4.81 \\
$1: 400$ & 1.269 & 0.214 & 5.93 \\
$1: 800$ & 1.108 & 0.179 & 6.19 \\
$1: 1600$ & 0.719 & 0.160 & 4.49 \\
\hline
\end{tabular}

HRP, horseradish peroxidase; $\mathrm{P} / \mathrm{N}$, ratio between positive and negative sera; Ab, antibody; IgG, immunoglobulin G.

negative swine serum were tested under optimal conditions by indirect ELISA. The highest OD450 was 0.194 and the lowest OD450 was 0.103 . The average value is 0.142 and the standard deviation is 0.02463 . $\mathrm{X}+3 \mathrm{~S}=0.22$. Therefore, the cut-off value is 0.22 . A serum sample was considered positive if its $\mathrm{P} / \mathrm{N}$ value was $\geq 0.22$. At this value, the highest efficiency of sensitivity and specificity was achieved. With this value, four of the 92 positive samples determined by neutralization test were negative by indirect ELISA, and two of the 28 negative sera by neutralization test were tested positive by indirect ELISA. The ELISA gave $95.7 \%$ (88/92) sensitivity and $92.9 \%$ (26/28) specificity, respectively (Table III). The result for 265 clinical swine serum samples from Baoding demonstrated that 217 samples were positive. The antibody positive rate against EMCV was $81.9 \%$. It indicated that swine in Baoding infected with EMCV is a serious issue.
Table III. Presence of antibodies against EMCV as determined by iELISA and neutralization test of 120 swine serum samples from pig farms.

\begin{tabular}{lccc}
\hline & \multicolumn{2}{c}{ Neutralization test } & \\
\cline { 2 - 3 } iELISA $^{\text {a }}$ & Positive (+) & Negative (-) & Total (n) \\
\hline Positive (+) & 88 & 2 & 90 \\
Negative (-) & 4 & 26 & 30 \\
Total & 92 & 28 & 120 \\
\hline
\end{tabular}

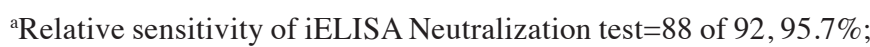
relative specificity of iELISA Neutralization test $=26$ of $28,92.9 \%$. EMCV, encephalomyocarditis virus; iELISA, indirect ELISA.

\section{Discussion}

EMCV mainly causes piglet encephalitis, myocarditis and sudden mortality. Many countries and regions have reported an outbreak of the disease in swine herds. For the first time in 2005 in China, EMCV was isolated in dead piglets and aborted fetuses (10). A serological survey indicated that EMCV has become a danger to the healthy development of China's pig industry (8). This research using the prokaryotic expression vector of pET32a constructed EMCV VP1 gene recombinant expression plasmid pET32a-VP1, and in E. coli BL21 (DE3) strains successfully expressed protein VP1. Although the prokaryotic expression system cannot be modified, it is often used to express high quantities of foreign proteins at low cost. The current study used the prokaryotic expression system to 
demonstrate that, following induction by IPTG, recombinant VP1 protein is highly expressed. The results indicated that the accumulation of VP1 protein in the cytoplasm may have been due to an imbalance between the rapid expression of exogenous protein and its removal from the cell. The cultivation conditions and availability of the amino acids components of VP1 may have also been influential factors regarding the level of VP1 expression (11). Busuttil et al previously indicated that the soluble protein ratio may be increased in the following ways: Reduction in temperature; co-expression with a molecular chaperone; and addition of a chemical reagent in the process of induction (12). Meanwhile, other experiments by our group attempted to change several conditions, including temperature, speed of the shaking table, and the dosage and frequency of IPTG administration; however, the majority of the recombinant protein was present in inclusion bodies (data not shown). To improve the expression of soluble protein, other methods should be trialed in future studies.

In addition, the present study also identified that recombinant VP1 was a high activity protein in terms of sensitivity and specificity. This may form a basis for the development of clinical diagnostic kits and genetic engineering vaccines.

EMCV is a pathogen of zoonosis and can be diagnosed by RT-qPCR $(13,14)$. This method has high sensitivity, strong specificity and a simple operation. It has been widely used in the diagnosis of diseases of pigs. Nevertheless, this ELISA provided an alternative, inexpensive and rapid serological detection method that would be suitable for screening for anti-EMCV antibodies titers on a large scale. In the current study, the authors established an indirect ELISA to detect the antibodies against EMCV with the recombinant $\mathrm{pET} 32 \mathrm{a}-\mathrm{VP1}$ epitope protein in swine. By using checkerboard titration tests, the optimal antigen concentration and the dilutions of serum was obtained. Meanwhile, the dilution of the secondary antibody is important as well.

EMCV infections are a worldwide issue. In Panama, a strain of EMCV was isolated from sick pigs in 1958 for the first time. By the 1970s, many countries, including Australia, Greece, Belgium, South Africa, Italy and Japan had reported the disease (15-17). The positive rate of neutralizing antibody in serum ranges between 2 and $87 \%$ (18). In the Netherlands in 2006, 3,237 sera from 277 pig breeding farms were analyzed to identify antibody levels. $9.3 \%$ of the serum samples were positive, $58.8 \%$ of the sow was positive (19). In Tianjin, 295 serum samples from 66 pig breeding farms in seven counties were measured with indirect ELISA for the antibody levels and $84.75 \%$ of the serum were positive (20). In 13 provinces of China, 3,250 serum samples from the 46 farms were measured with this method for the antibody levels. The rate of antibody positive is $72 \%$ (21).

In conclusion, the indirect ELISA assay was developed successfully for the detection of antibodies to EMCV with high levels of sensitivity and specificity. The assay will be useful test for large-scale serological survey in EMCV infection and monitoring antibodies titers against EMCV.

\section{Acknowledgements}

The present study was supported by the Natural Science Foundation of Hebei Province in China (grant no. C2016204191).

\section{References}

1. Palmenberg AC, Kirby EM, Janda MR, Drake NL, Duke GM, Potratz KF and Collett MS: The nucleotide and deduced amino acid sequences of the encephalomyocarditis viral polyprotein coding region. Nucleic Acids Res 12: 2969-2985, 1984.

2. Sin JI, Sung JH, Suh YS, Lee AH, Chung JH and Sung YC: Protective immunity against heterologous challenge with EMCV by VP1 DNA vaccination: Effect of coinjection with a granulocyte-macrophage colony stimulating factor gene. Vaccine 15: 1827-1833, 1997

3. Suh YS, Ha SJ, Lee CH, Sin JI and Sung YC: Enhancement of VP1-specific immune responses and protection against EMCV-K challenge by co-delivery of IL-12 DNA with VP1 DNA vaccine. Vaccine 19: 191891-1898, 2001.

4. Carocci M and Bakkali-Kassimi L: The encephalomyocarditis virus. Virulence 3: 351-367, 2012.

5. Gelmetti D, Meroni A, Brocchi E, Koenen F and Cammarata G: Pathogenesis of encephalomyocarditis experimental infection in young piglets: A potential animal model to study viral myocarditis. Vet Res 37: 15-23, 2006.

6. Krylova RI and Dzhikidze EK: Encephalomyocarditis in monkeys. Bull Exp Biol Med 139: 355-359, 2005.

7. Spyrou V, Maurice H, Billinis C, Papanastassopoulou M, Psalla D, Nielen M, Koenen F and Papadopoulos O: Transmission and pathogenicity of encephalomyocarditis virus (EMCV) among rats. Vet Res 35: 113-122, 2004.

8. Ge X, Zhao D, Liu C, Wang F, Guo X and Yang H: Seroprevalence of encephalomyocarditis virus in intensive pig farms in China. Vet Rec 166: 145-146, 2010.

9. Yuan W, Wang J, Sun M, Zheng Y, Li L, Zhang X and Sun J: Rapid detection of encephalomyocarditis virus by one-step reverse transcription loop-mediated isothermal amplification method. Virus Res 189: 75-78, 2014.

10. Ge X, Yang H, Guo X, Lu Y, Wang F, Chen Y and Cha Z: Isolation and characterization of porcine encephalomyocarditis virus. Chin J Anim Vet Sci 38: 59-65, 2007 (In Chinese).

11. Long Y, Liu H and Wang Z: Purification and renaturation of recombinant inclusion. Heilongjiang Animal Science and Veterinary Medicine 16: 70-71, 2008 (In Chinese).

12. Busuttil BE, Turney KL and Frauman AG: The expression of soluble, full-length, recombinant human TSH receptor in a prokaryotic system. Protein Expr Purif 23: 369-373, 2001.

13. Kassimi LB, Gonzague M, Boutrouille A and Cruciere C: Detection of encephalomyocarditis virus in clinical samples by immunomagnetic separation and one-step RT-PCR. J Virol Methods 101: 197-206, 2002.

14. Maurice H, Nielen M, Stegeman JA, Vanderhallen H and Koenen F: Transmission of encephalomyocarditis virus (EMCV) among pigs experimentally quantified. Vet Microbiol 88: 301-314, 2002.

15. Koenen $\mathrm{F}$ and Vanderhallen $\mathrm{H}$ : Comparative study of the pathogenic properties of a Belgian and a Greek encephalomyocarditis virus (EMCV) isolate for sows in gestation. Zentralbl Veterinarmed B 44: 281-286, 1997.

16. Kudo H, Yoshizawa S, Hiroike T and Hirose O: A retrospective serological survey of the encephalomyocarditis virus among pigs in Chiba prefecture, Japan. J Vet Med Sci 57: 793-795, 1995.

17. Murnane TG, Craighead JE, Mondragon H and Shelokov A: Fatal disease of swine due to encephalomyocarditis virus. Science 131: 498-499, 1960

18. Maurice H, Nielen M, Brocchi E, Nowotny N, Kassimi LB, Billinis C, Loukaides P, O'Hara RS and Koenen F: The occurrence of encephalomyocarditis virus (EMCV) in European pigs from 1990 to 2001. Epidemiol Infect 133: 547-557, 2005.

19. Augustijn M, Elbers AR, Koenen F and Nielen M: Estimation of seroprevalence of encephalomyocarditis in Dutch sow herds using the virus neutralization test. Tijdschr Diergeneeskd 131: 40-44, 2006.

20. Dong Y, Huang J, Wang J, Zhao Y and Li L: Development and application of an indirect ELISA for detection of antibodies against EMCV. Chin Anim Quar 25: 30-33, 2008 (In Chinese).

21. Zhang J, Ge X, Ma L, Chen Y, Cha Z, Guo X and Yang H: Investigation of serum with infected EMCV swine in large-scale pig farms. Chin J Vet Sci 43: 7-9, 2007 (In Chinese). 